Revista Española de Filosofía Medieval, 6 (1999), pp. 11-24

\title{
LA NATURALEZA Y EL ESPACIO EN LA ESTETICA MEDIEVAL
}

\author{
Joaquín Lomba \\ Universidad de Zaragoza
}

\section{RESUMEN}

El objetivo de este artículo es mostrar cómo el arte medieval (cristiano occidental y musulmán) expresa una naturaleza y espacio que depende del concepto de naturaleza y de espacio que se tiene. Ahora bien, este concepto es distinto en el mundo cristiano y en el musulmán. Los dos sostienen que la naturaleza y el espacio, a diferencia de Grecia, son creados, dependen de un Dios transcendente. Sin embargo, la naturaleza y el espacio en el arte musulmán resulta mucho más dependiente del Creador, lo cual se manifiesta en sus formas artísticas.

Palabras clave: Naturaleza, Espacio, Estética, Medievo, Formas, Islam.

\section{ABSTRACT}

The subject of this article is to expond how the medieval art (christian-european and muslim) express a nature and space that depends on the own concept of the nature and space. On the other hand, his concept is different in the christian world and in the muslim one. Both of them mantain that nature and space, in contrast to Greece, are created, and depend on a Transcendental God. Hawever, the nature and space in the muslim art is more dependent on Creator than in the christian one, and that become evident in the artistic forms.

Key words: Nature, Space, Beauty, Aesthetics, Medieval, Forms, Islam.

Como he mostrado en otros lugares ${ }^{1}$ una de las claves interpretativas del arte de cada época estriba en el concepto que en ella se tenga de «naturaleza» y de «espacio» contenido en dicha naturaleza. Así, como ha mostrado, por ejemplo, Camón Aznar, el cubismo coincide con la física de los «quanta» de Plank, así como muchas corrientes del arte contemporáneo son simultáneas a la teoría

1 Lomba, J., Principios de Filosofia del arte griego, Anthropos, Barcelona, 1987, «Physis y mímesis en el arte griego», Homenaje al Prof. D. Antonio Beltrán, Zaragoza, 1985, p. 883-887, «Aproximación al arte griego y medieval» en Horizontes de la Hermenéutica, Universidad de Santiago de Compostela, 1998, pp. 635-649, «Orden cósmico y moral en la música griega», en La realidad musical, Ed. Juan Cruz, Cruz, EUNSA, Pamplona, 1998, p. 385-406, «Apuntes para la estética musulmana», Turia, Teruel, 1986, p. 71-82, La razón y la estética medieval», Actas del I Congreso Nacional de Filosofia Medieval, Zaragoza, 1992, p. 65-93, «Aproximación a una estética musulmana», en La filosofía y sus márgenes. Homenaje al Prof. Carlos Baliñas, Universidad de Santiago de Compostela, Santiago de Compostela, 1997, p. 349-377. 
de la relatividad de Einstein ${ }^{2}$. En consecuencia, quisiera esbozar brevemente algunos apuntes sobre la naturaleza y el espacio expresados en el arte medieval.

Pero antes quisiera hacer algunas anotaciones. Primera, en estas consideraciones tendré en cuenta no solo el arte cristiano occidental (prescindo del bizantino) sino también el musulmán. Y ello, no solo por razones cronológicas sino también porque ambas formas de hacer arte expresan, desde un mismo monoteísmo creacionista de tradición abrahámica, distintas maneras de concebir la naturaleza y el espacio. Por lo demás, esta comparación entre ambas formas de hacer arte aclarará tanto a la una como a la otra. Ahora bien, hay que advertir que, aunque se trate de dos religiones monoteístas y creacionistas, la manera en que expresarán la naturaleza y el espacio no solo dependerá primera y fundamentalmente del concepto interno que ambas religiones tengan de naturaleza y de espacio, sino que también influirán en la configuración externa de las formas las tradiciones culturales en las que nacen, se desarrollan y encuadran: el cristianismo dentro del helenismo y de la romanidad y el islam en el interior de la tradición persa y bizantina, sobre todo. Segunda, que no voy a echar mano fundamentalmente de textos de pensadores antiguos o medievales, aunque no lo excluyo, sino que trataré de interpretar el arte medieval desde el mismo concepto de naturaleza y cspacio que se expresa en las formas artísticas. ${ }^{3}$ Tercera, que no voy a ver el arte como como comunicación, como lenguaje que me habla de la naturaleza y el espacio sino como expresión de las mismas. ${ }^{4}$ Cuarta, que me voy a ceñir al espacio y naturaleza expresados en la arquitectura, dejando de lado la pintura y escultura, así como otras manifestaciones artísticas. ${ }^{5} \mathrm{Y}$, finalmente, que no voy a abordar el tema desde el punto de vista de historiador o crítico de arte, que no es mi oficio, sino desde la filosofía.

\section{CONCEPTO DE NATURALEZA}

Ante todo, el concepto de naturaleza y espacio que provenía de Grecia y Roma y en cuyo seno emerge el arte cristiano occidental, era el plasmado, sobre todo, por Aristóteles cuando en la Física defi-

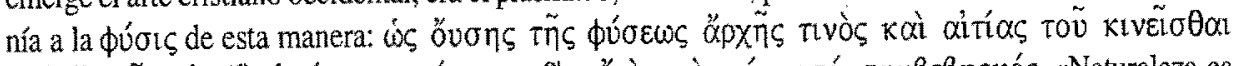

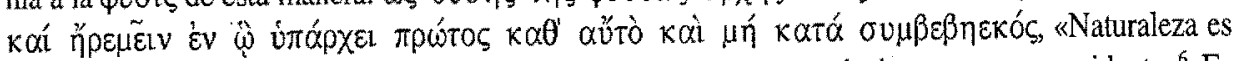
aquello que tiene en sí el principio del movimiento y del reposo, por sí mismo y no por accidente ${ }^{6}$. Es decir: la naturaleza era algo totalmente autónomo, cerrado en sí mismo y dotado de unas leyes causa-

2 Camón Aznar, J., Filosofía del arte modemo, discurso leído en la recepción de la Academia de Ciencias Políticas y Morales, Madrid, 1965, El ante desde su esencia, Espasa Calpe, Madrid, 1968, Picasso y el cubismo, Espasa Calpe, Madrid, 1956.

3 Consideraciones del arte medieval y de su estética hechas a través de los textos, pero también desde un punto de vista teórico pueden verse en los excelentes trabajos de Bnuyne. E., Estudios de Estética Medieval, Gredos, Madrid, 1958, 3 vols. La estética de la Edad Media, Visor, Madrid, 1987; Eco, U., Arte y Belleza en la estética Medieval Lumen, Barcelona, 1997. Y, para la estética musulmana: Puerta Vilchez, J.M., Historia del pensamiento estético árabe. Al-Andalus y la estética árabe clásica, AKAL, Madrid, 1997.

4 Distingo con Dufrenne entre arte como lenguaje y arte como expresión. Una obra puede narrar, decir, comunicar cualquier hecho, personaje o acontecimiento, pero no reside en ello su valor estético, sino en el qué y el cómo lo expresa (Dufrenne, M., Fenonenología de la experiencia estética, Ed. Román de la Calle, Valencia, 1982, dos vols).

5 Puede verse, Van der Ven, C., El espacio en la arquitectura, Cáledra, Madrid, 1977.

6 Aristóteles, Fisica, 192 b 20. 
les según las cuales el funcionamiento de lo natural circulaba de una manera automática y necesaria, frente a lo artificial, producto de la rexví que dependía de un artesano exterior a su obra a la cual y que configuraba según las leyes de su oficio. ${ }^{7}$ La naturaleza poseía en sí y por síla fuerza necesaria para configurarse a sí misma. Los dioses pertenecían, por otro lado, a la misma naturaleza y estaban sometidos a sus mismas leyes solo que situados en un nivel superior y con el privilegio de poder regir el destino de los hombres. Por otro lado, la naturaleza, y dentro de ella los dioses, eran eternos, nadie los había hecho. En todo caso, según Platón, como nos lo cuenta en el Timeo, el Demiurgo, una especie de etemo Dios Fabricante se limitó a elaborar un mundo construyendo primero el alma del mismo

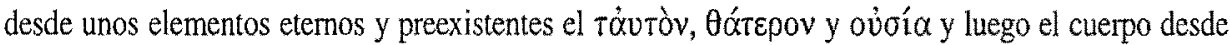
una materia informe también etema, la $\chi \omega ́ p \alpha$, a los cuales imprimió una estructura esencialmente matemática, configurando así un todo organizado, el kóouoc. A ello volveré más adelante. Y el Motor Inmóvil de Aristóteles solo era la causa última de todo movimiento cósmico, no el causante de su existencia. Grecia y Roma no tuvieron nunca el concepto de creación desde la nada, de donación de la existencia por parte de un ser Superior.

Por eso, la aparición del monoteísmo creacionista judío, cristiano y musulmằn hizo variar sustancialmente este concepto de naturaleza. Esta ya no era algo autónomo y eterno sino que dependía de Un solo Ser Absoluto, el único Necesario. Y esa dependencia empezaba por el hecho de que la naturaleza no se bastaba a sí misma para ser, sino que había sido creada por Dios sacándola de la nada a la existencia. Esta nada la atravesaba de arriba abajo de modo que en cualquier momento podía hundirse de nuevo en ella si es que quien la había sacado de ella, lo quería. Y si tenía leyes, era porque ese Absoluto Creador se las había dado graciosamente. Este Dios es, además y sobre todo, transcendente, «lo otro» del mundo, que está fuera de la naturaleza, del espacio y del tiempo: es simplemente eterno. Y eterno, no como era la naturaleza en Grecia, en el sentido de que «duró», «dura» y «durará» siempre, sin comienzo ni fin temporal, sino que ese Dios existe al margen del tiempo, sin tiempo y sin poder dejar de existir. Tan lo «otro» de la naturaleza y del espacio es Dios.

Por otro lado, el mundo, la naturaleza y, sobre todo, el ser humano, con la aparición de esta nueva idea del mundo y de su Hacedor, tienen un destino: el mismo Dios que la creó de la nada. La vida natural del hombre tiene un nuevo sentido: más allá de la naturaleza y más allá de la muerte.

El tema es, pues, cómo expresar en el arte esta nueva situación planteada por los monoteísmos: haciéndose eco de esa naturaleza contingente, creada, colgada sobre el abismo de la nada por el delgado hilo de la voluntad de quien la sacó de esa misma nada. $Y$, a la vez, expresar el destino último a la que está vocacionada: el Dios que la cré.

\section{NATURALEZA, ESPACIO Y LUGARES}

Para dar respuesta a esta cuestión y poder aplicarla adecuadamente al arte cristiano (distinguiendo en él el románico y el gótico y prescindiendo, como he dicho, del bizantino) y al musulmán, convendrá asentar antes algunas bases.

7 Un ejemplo claro inspirado en Aristóteles es el de una semilla de trigo, objeto natural, que produce por sí misma, y según sus propias leyes el movimiento que la lleva a ser espiga de tngo. Mientras que un lecho nunca engendrará por sí mismo un lecho, sino que habrá de ser un carpintero quien desde fuera de la madera fabrique el lecho según las leyes de la carpintería. 
Ante todo, y siguiendo con la línea aristotélica (que en este punto será el que, en general, prevalezca en el Medievo, aunque combinándose, como veremos con el platonismo y neoplatonismo), el espacio se identifica con la naturaleza dado que ésta, repleta de ser (puesto que la nada no existe), constituye el espacio de todas las cosas existentes. Aristóteles definió el espacio como el con-

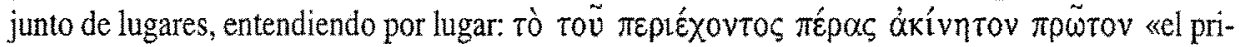

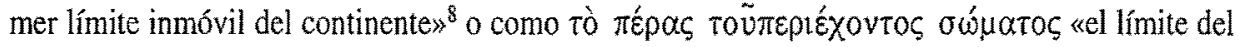
cuerpo continentes, ${ }^{9}$ En otras palabras: el lugar es aquella zona interior de un cuerpo que roza y limita con la superficie exterior del cuerpo al que abarca y contiene. Por ejemplo: el lugar de esta revista sería la superficie interior del aire que está envolviendo las tapas externas de la misma. Y el lugar del aire, la superficie interna de las paredes de la habitación que están abarcando y rozando la superficie externa del aire de la misma y así sucesivamente hasta llegar a la esfera de la luna la cual estaría a su vez en el lugar de la esfera del planeta siguiente en roce con la esfera de la luna. $Y$, finalmente, todas las esferas celestes estarían en el lugar que marca la superficie interior de la última esfera, la de las estrellas fijas, con la superficie exterior de la la esfera siguiente. Y este conjunto de seres localizados así, o mejor dicho, este total de lugares en que todos los cuerpos se rozan y tocan entre sí, constituye el espacio finito del universo entero, la naturaleza en su totalidad.

Ahora bien, este espacio, además de no ser un receptáculo vacío como lo será en Descartes, tampoco es, como en éste, homogéneo. Cada elemento (tierra, agua, aire y fuego) de que están compuestos todos los seres, tiene su «lugar natural»: la tierra tenderá a situarse abajo, el agua encima de ella, a continuación el aire y, por fin, en el arriba más alto, el fuego. Es la razón de que en un universo esférico y limitado, la tierra ocupe el centro del mismo, ya que ese centro es el abajo absoluto del mundo, de la naturaleza y del espacio. El lugar natural de la tierra es el centro, el abajo. Y, por encima de ella, los mares y los ríos, estando rodeados por el aire y éste por el fuego celeste, el arriba absoluto de todo el universo esférico. Y si alguien quita violentamente uno de estos clementos de su lugar natural, al cesar la violencia vuelve a él; es la razón de que una piedra lanzada al aire caiga al suelo. A falta de la ley de gravitación universal newtoniana ésta era la explicación aristotélica de la caída de los graves.

Y es que ese espacio lleno, compacto, es heterogéneo cualitativamente. El arriba es lo mejor, lo divino, lo bueno; y todo movimiento ascendente es algo que implica deseo de lo excelso, que aspira a lo mejor, a lo óptimo (por eso la cabeza está en lo más alto del cuerpo y por eso también los dioses están arriba). El abajo es lo malo, lo pesado, lo vil. La derecha es mejor que la izquierda (por eso el sol sale por oriente, por la derecha). Y lo delantero más noble que lo que está detrás (por eso los órganos más nobles y eficaces del hombre están delante). 


\section{NATURALEZA, ESPACIO Y LUGARES EXPRESADOS EN EL ARTE CRISTIANO OCCIDENTAL}

Estos planteamientos tienen su repercusión profunda en el arte medieval, solo que de manera muy distinta en el mundo musulmán y cristiano y, dentro de éste, en el románico y gótico.

Ante todo hay que tener en cuenta que el arte cristiano europeo propiamente tal se constituye al amparo, primero de las formas artísticas y arquitectónicas romanas y griegas (el bizantino tomará otros derroteros); y segundo, del pensamiento y filosofía griega. En consecuencia, pese a la consideración de un Dios como «lo otron de la naturaleza, la cual depende por completo de la omnipotencia divina, siendo ella en sí misma pura contingencia, pura nada, sin embargo, conserva ciertos vestigios del concepto de $\phi v ́ o t \varsigma$ al modo aristotélico. La naturaleza, entonces, depende ciertamente de Dios, pero, una vez creada tiene la posibilidad de funcionar autónomamente según las leyes que Dios le ha dado. En tal caso, la naturaleza, la materia, el espacio del arte cristiano europeo habrá de expresar simultáneamente la nadedad que es el mundo y la omnipotencia creadora de Dios, de un Dios hacia el cual tiende el cosmos entero creado por El y, sobre todo, el hombre.

Ahora bien, dentro del pensamiento griego que sublate en el arte cristiano occidental, hay dos corrientes que marcarán dos estilos distintos o dos maneras diferentes de expresar la naturaleza y el espacio, tal como he anunciado un poco más arriba. Uno es el platónico y neoplatónico; otro, el aristotélico.

Según el platonismo, la belleza se consigue mediante la introducción de la matemática en las formas arquitectónicas y musicales, las cuales constituyen dos formas de movimiento hecho ritmo. Dice Platón: «El movimiento, a mi entender, presenta no una sola forma, sino muchas. Un sabio podría enumerarlas en su totalidad; nosotros, si acaso, esas dos que conocemos [...]. Parece en verdad que así como los ojos han sido hechos para la astronomía, los oídos lo fueron para el movimiento armónico y que estas ciencias son como hermanas, al decir de los pitagóricos y de nosotros mismos, Glaucón, que comulgamos en ello». ${ }^{10}$ En cuyo texto la alusión al movimiento que se oye se refiere explícitamente a la música, pero la hecha a la vista no solo alude a la astronomía, como dice, sino también a la arquitectura. Platón y el propio Aristóteles consideran a la naturaleza como una inmensa obra de arte arquitectónica e incluso como un agente arquitectónico que produce belleza. ${ }^{11}$

Pero volviendo a Platón, es en el Timeo donde expone con toda minuciosidad las armonías, proporciones y ritmos, que antes anuncié, y que tanto la música como la arquitectura han de reproducir, como expresión de un cosmos ordenado aritmética y geométricamente, porque afirma Platón: «lo que aquí entiendo por belleza de la forma no es lo que el vulgo comprende generalmente bajo este nombre, como, por ejemplo, la de los objetos vivos o de sus imitaciones, sino algo de rectilineo y de circular, y las superficies compuestas con lo rectilíneo y lo circular, por medio del com-

10 Platón, República, 531 a 20.

11 Dice Aristóteles: «La naturaleza, que es un artista-arquitecto, Onut ovpyno oo ov, reserva a los que la estudian unas agradables maravillas, a condición de que se remonte uno a las causas y se vea verdaderamente filosofon (Sobre las partes de los animales, 645 a). 
pás de la cuerda y de la escuadra. Estas formas no son, como las otras, bellas solo bajo ciertas condiciones, sino que son siempre bellas en sí mismas» ${ }^{12}$

Este espíritu geométrico y aritmético regirá todo el arte medieval cristiano occidental, porque se pensará como lo hizo Platón que la naturaleza es esencialmente orden matemático impreso por Dios en la materia y en el espacio, al igual que el Demiurgo platónico lo hizo con la Xúpa eterna o materia informe. Y el mismo ideal de proporción y armonía medidas seguirá en el Renacimiento y estilos posteriores europeos. También en el arte musulmán habrá un espíritu matemático, pero surgido de otras fuentes y como expresión de otra manera de ver la naturaleza y el espacio. A este orden matemático volveremos más adelante.

Por parte del neoplatonismo, el mundo, la naturaleza viene a ser como una emanación del Uno, emanación que en sentido descendente a través de diversos Intelectos, Almas y Cuerpos Celestes se llega a la materia o $0 ّ \lambda \eta$, el ínfimo grado del ser, origen de lo vil del hombre, de la dispersión y multiplicidad, aquello que con su densidad y pesantez lo arrastra al mal y que, en consecuencia ha de despojarse de ella para remontarse a la Unidad de Dios, de un Dios que, sobre todo se halla en el interior del hombre, en la más íntima recámara de nuestro yo y conciencia, de acuerdo con el más fiel agustinismo.

En arte podríamos decir que esta manera de expresar la naturaleza corresponde al románico. Densos muros con pequeñas aberturas por cuyos vanos entra la luz del sol con una función muy especifica: la de iluminar las pinturas, imágenes y representaciones que hay en el interior para que los fieles aprendan la verdad de las Escrituras y el mensaje evangélico en ellos pintados o esculpidos..$^{13}$ Pero, a la vez, esa luz, entreverada de claroscuros, invita al recogimiento, a la entrada del hombre en sí mismo donde hallará la Verdad. según el espíritu neplatónico de Agustín de Hipona: «Noli foras ire, in te ipsum redi, in interiore homine habitat veritas, et si tuam naturam mutabilem inveneris, transcende te ipsum ${ }^{14}$.

Por otra parte, las grandes masas de piedra, los gruesos paramentos, expresión de una naturaleza y espacios materiales, pesados y toscos, se santifican, sacralizan y elevan mediante dos registros. Uno, por el simbolismo de las plantas en forma de cruz latina. La materia innoble se santifica al haber servido de cruz para Cristo lo cual se expresa con esa manera de trazar los templos. Otro, mediante las puntiagudas torres que, por un lado, apuntan al destino eterno del hombre, arriba, en el cielo, recordando a los fieles que es allí donde está su verdadero destino y vocación, lejos de la materia. Y, por otro, arrastrando la pesantez de la materia hacia lo alto, como si se tratase de unos fuertes tirantes que arrancasen de su lugar natural a la materia, del abajo donde reside por esencia, para violentarlo y subirlo a otro lugar natural, al del fuego y de la luz, al arriba absoluto donde Dios está en el Cielo. ${ }^{15}$ Así, el centro de atención del templo, visto desde el exterior, se situará en el cielo. Pero una vez dentro, dicho centro estará en el tabemáculo, en el altar, hacia el que el espacio jalo-

12 Platón, Filebo, 51 a 10.

13 Para estudiar el tratamiento de la luz en el arte, ver Nieto Alcaide, V., La luz, símbolo y sistema visual, Cátedra, Madrid, 1989.

14 San Agustín, De vera religione, 39, 72.

15 Para el tratamiento de los diversos centros geométricos, de gravedad y de atención en las obras de arte, ver: Amheim, R., El poder del centro, Alianza, 1984. 
nado por las columnas nos arrastrará hacia él con la misma fuerza que el espacio de las torres exteriores nos lanzaba hasta el cielo.

El gótico, por el contrario, sublima y sacraliza la misma materia en sí misma considerada. Es que la filosofía aristotélica ha hecho su aparición, con el encumbramiento de las substancias individuales materiales que ya no son degradación de las ideas-modelo de Platón ni desvalorización ínfima del proceso emanativo desde el Uno del neoplatonismo. La substancia material, por sí misma, ya es valiosa. Y no solo eso, sino que la misma substancia, incorporada a la teología cristiana, se sublima aún más, se puede divinizar. Dios se hizo carne, lo cual, dentro del aristotelismo tiene un valor muy especial, ya que desde este punto de vista, toda materia es divinizable, susceptible de cobrar un valor sobrenatural.

De este modo, y en consecuencia, desaparecen los pesados muros para dar paso a grandes y luminosos rosetones y vidrieras, ejemplar característico de lo cual es la Santa Capilla de Notre Dame de París. Los muros de piedra se han aligerado hasta el punto de convertirse en estrechos paneles de cristal que parecen levitar por sí mismos, a través de los cuales ya no es la luz natural del sol la que penetra para que veamos, como en el románico, lo que en la piedra hay pintado o esculpido, sino que los mismos muros ya son luz sobrenaturalizada que me enseña la vida de los santos, los hechos de la Escritura, las Verdades de la fe. Igualmente, los capiteles, los arcos, nervaturas, arbotantes y torres se han revestido de finísimos y delicados encajes de piedra, expresando así el valor del adorno individual de las substancias naturales, la miniatura de su belleza. Y las torres ya no hace falta que sean tan gruesas como si con su potente volumen tuviesen que representar la fuerza con que tienen que tirar de la materia hacia arriba, como ocurría en el románico. Se han estilizado porque la misma materia se ha sobrenaturalizado y no precisa del arrastre forzado del estilo anterior. Por eso ya casi solo cumplen con la función deíctica del más allá, de los cielos, sin dejar de seguir tirando del cuerpo del templo, ahora más ligero, hacia el cielo.

Bajo otro punto de vista, el espacio gótico ha adquirido una nueva dimensión: la luminosa. Junto con Aristóteles ha entrado también la metafísica de la luz aviceniana en Occidente, así como la optica y teoría estética de la luz de al-Haytham o Alhazem. Con ello, el protagonista del interior de las catedrales góticas es la luz, una luz-espacio o un espacio-luz porque parece que ambos se engendran el uno al otro mutuamente. Una luz coloreada en que las penumbras que señalaban la intimidad de la conciencia donde se hallaba Dios en el románico, han desaparecido. Si en muchas ocasiones, tanto en el románico como en el gótico, el espacio era visto como el mismo Dios o como representación suya, máxime cuando el espacio de las plantas era trazado en forma de cruz latina, ahora lo es más en el gótico, cuando incluso se piensa que Dios es luz deslumbrante.

\section{NATURALEZA Y ESPACIO EN EL ARTE MUSULMÁN}

El tratamiento de la naturaleza en el islam es completamente distinto. El monoteísmo musulmán es mucho más estricto y cerrado, al no admitir la Trinidad. Junto a ello o como consecuencia, dos características más de ese monoteísmo: La primera, que Dios es tan Uno que es imposible conocerlo, al menos según la teología más oficial. Será el sufismo o mística musulmana el que abrirá las puertas a un conocimiento y amor de Dios que, como buen amor, tendrá que estar provocado por la belleza de un mundo que es reflejo de la belleza de Dios. Dice un hadith o tradición pro- 
fética: «Dios es Bello y ama la belleza». Y a los noventa y nueve nombres de Dios en el Corán se les llama «los bellos nombres de Dios». De ahí que ningún símbolo del arte musulmán pueda expresar a Dios mismo, aunque sí a su Trono y a los Cielos donde habita. Dios, por tanto, ya de entrada, no será algo a lo que el arte aluda deícticamente con su minaretes, cúpulas y torres, sino un a priori aceptado por la fe. Dios, se supone que existe y por tanto, el arte tendrá que expresar que eso es así.

La otra característica es que Dios es absolutamente Omnipotente; y ello de tal manera que nada fuera de El tiene poder ni es algo. El islam se constituyó en su cuna natal sin contagio alguno inicial con el mundo griego, como ocurrió con el pensamiento cristiano occidental. En consecuencia,

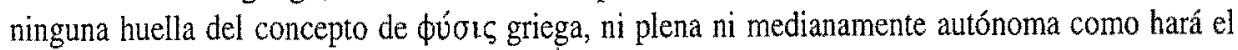
arte cristiano occidental. De tal manera que, la filosofía musulmana, a la hora de traducir la palabra фứrı lo hace mediante el término «tabî̀a» que significa huella, impronta: el mundo no es más que una simple huella, un rastro huidizo, frágil, como lo es la estela que un cometa deja tras de sí y que, en cuanto el cometa se esconde en las profundidades inaccesibles de los cielos, ella se esfuma. Y los primeros filósofos, como al-Fârâbî y Avicena, concibieron al mundo como un simple posible, sin ningún derecho propio a existir, frente al único Ser Necesario que no puede en modo alguno dejar de existir, donador exclusivo y libre de la existencia. Y, por fin, la teología más oficial del islam, la ash' arita, bajo el magisterio sobre todo de al-Bâqillânî (muerto en 1013), sostiene que tal es el poder de Dios y tal la nada, del mundo que éste se halla constituido por multitud de átomos creados continuamente por Dios y combinados por El en cada momento según su libre criterio para formar los distintos seres de la naturaleza. Todo el poder está en Dios y en modo alguno se puede hablar de causalidad y de leyes de la naturaleza: solo cxiste la acción de Dios (no de las cosas ni de las causas) y costumbres en Dios que son las que llamamos leyes. La piedra cae hacia abajo porque Dios tiene la costumbre de hacerlo así El mismo. Pero si en un momento dado decidiera otra cosa, ocurriría al revés, por ejemplo: que ascendiera.

Todo lo dicho tiene su expresión en el arte musulmán. ${ }^{16}$ Citaré solo algunos ejemplos. La utilización de mocárabes que hacen como de diminutas y atómicas pechinas para pasar de la figura hexagonal o circular de las cúpulas a la cuadrada de la base o que adornan como con encajes los arcos de interiores, de puertas y ventanas. La ruptura de la luz mediante celosías y surtidores. La utilización de grandes estanques que hacen de espejos que reflejan la naturaleza celeste a la vez que también reproducen los edificios que están a su alrededor invirtiendo su figura o distorsionándola cuando mueve el viento la superficie del agua, como expresión de la fragilidad y futilidad de las construcciones, muchas veces hechas, además, de materiales endebles, como ocurre en el patio de los Arrayanes de la Alhambra de Granada. Es que la naturaleza, el espacio que están expresando son del mismo modo frágiles y débiles. Solo Dios es el fuerte, el Uno, el Inmutable, el Poderoso. La utilización de estanques, dicho sea de paso, tiene también el sentido místico del espejo, tan utilizado por el sufismo que tanto influyó y encarnó el espíritu estético del islam. Otro registro utilizado para expresar la nada de la naturaleza es la ruptura de espacios mediante arcos y bosques de columnas, como puede verse en la Mezquita de Córdoba o en el Patio de los Leones de Granada.

16 Ver mi ya citado artículo «Aproximación a una estética musulmanà, en La filosofia y sus márgenes. Homenaje al Prof. Carlos Baliñas. 
Es curioso que algunos han indicado, y no sin razón, como Titus Burckhardt, que el espacio del arte musulmán ofrece la misma estructura sorpresiva, inesperada y quebrada que el texto coránico; y no tiene nada de particular, dada la similitud del estilo y lengua árabes y el arte. ${ }^{17}$ Expresión de cuanto vengo exponiendo es también a profusión de casi infinitos y dimintuos azulejos de colores que rebotan en múltiples irisaciones la luz del sol rompiendo así cualquier superficie homogénea, una, autónoma, que quisiera rivalizar con la única Unidad que hay, la de Dios. Luz reflejada que, además, representa el acto único creador de Dios que con un solo movimiento de su voluntad hizo un casi infinito número de creaturas, variadas, diminutas y evanescentes como son los reflejos de los minúsculos colores que van cambiando conforme camina la única luz del sol por los cielos durante el día. En fin, podrían citarse más detalles en los que se expresa en todo momento que, por un lado, la naturaleza es bella, que emborracha los cinco sentidos, que sacia al hombre de placer y felicidad, pero que en sí es nada ya que lo único que es de verdad es Dios que se supone a priori con la fe más firme que ha hecho todo ésto.

\section{NATURALEZA Y ESPACIO MATEMATIZADOS}

Ya antes se dijo que según la concepción pitagórica y platónica del mundo, el cosmos, la naturaleza y el espacio eran un conjunto fundamentalmente ordenado aritmética y geométricamente. Una geometría y aritmética que quedaban encerradas en unidades estrechas, como lo es la naturaleza y el espacio, el mundo, que también conforman una unidad limitada, circular, y como lo es Dios, también que es Unico y que ha pensado al mundo de esta manera matemática. Es entonces cuando tanto en la teoría como en la práctica, el orden, la armonía, la proporción son las reglas imperantes del arte cristiano occidental del Medievo. Se hace presente en todo momento aquello de San Agustín: «Siento que nada me causa más placer que la belleza, y en la belleza las formas, en las formas las medidas y en las medidas los números $\rangle^{18}$ que recogía la antigua tradición de Vitruvio, tan omnipresente en la estética medieval, el cual afirmaba: «La proporción es una correspondencia de medidas entre una determinada parte de los miembros de cada obra y su conjunto o una concordia uniforme entre la obra entera y sus miembros, y una correspondencia de cada una de las partes separadamente con toda la obram. ${ }^{19}$

17 Así se expresa Burckhardt: «El artê plástico del Islam es en cierto modo reflejo de la palabra del Corán. Indudablemente es muy difícil captar el principio por el que este arte se vincula al texto del Corán, no en su aspecto narrativo, que no cumple función alguna en el arte habitual en el Islam, sino en el de las estructuras formales, pues el Corán no sigue ninguna ley de composición, ya se trate de la extraña desconexión en el encadenamiento de sus temas, ya de su formulación verbal, que escapa a todas las reglas de la métrica. Su ritmo, aunque potente y penetrante, no sigue ninguna medida fija: totalmente imposible de predecir, mantiene a veces una rima insistente como un redoble de tamber, $y$ de repente varia su amplitud y su compás, cambiando la cadencia de forma tan inesperada como sorprendente. [...]. El arte árabe tanto la poesía y la música como las artes plásticas- gusta de repetir ciertas formas y de intercalar variantes repentinas e imprevistas sobre este fondo repetitivo» (El arte del islam, Ediciones de la Tradición Unánime, Palma de Mallorca, 1988 p. 56-57).

18 San Agustín, De ordine, II, 15.

19 Vitruvio, De architectura, III, $1 ; 1,2$. 
De esta manera se expresaban dos cosas a la vez en el arte cristiano occidental: la unidad armónica de la naturaleza y el espacio y la unidad inteligente del Dios Uno y Sabio que ordenaba de esa manera el cosmos.

Ahora bien, este planteamiento es completamente distinto en el arte musulmán, donde la proporción y la matemática también juegan un papel fundamental pero con un signo por completo diferente.

En primer lugar, el arabesco, en su forma de lacería principalmente, obedece a un espíritu matemático y geométrico propio de la cultura árabe que, además, en sus formas repetitivas y entrelazadas, tiene mucho que ver con la estructura de la lengua árabe, como muy bien lo ha mostrado Kamâl Bullâta. ${ }^{20}$ En segundo término las lacerías no solo tienen una función matemática como objetivo primero sino que son, sobre todo, portadoras y recipientes del color, protagonista principal, como bien lo mostraron Ibn Hazm de Córdoba y el gran teórico de la óptica Alhazem. Tercero, la índole abstracta del arabesco no trata nunca de imitar puntualmente la naturaleza, el espacio real, el cosmos, sino que se remonta a una abstracción de la misma, matematizada y repetitiva. Con una repetición nunca cerrada en sí misma, sino prolongada indefinidamente. Nunca hay estructuras formales cerradas, unitarias porque, en definitiva, lo que se está queriendo decir es que este mundo, reducido a una abstracción es indefinido, no unitario, no limitado en unas fronteras que lo hagan uno y autónomo, porque uno solo es Dios.

Curiosamente, esta expresión de la naturaleza que nos remite al apriori de la Unidad de Dios, se encuentra en ocasiones en el hecho de que en las decoraciones vegetales y en las lacerías hay una sola linea que, retorciéndose, serpenteando, va recorriendo el arabesco entero recordando así el tema de la Unidad divina.

Por la misma razón, las plantas y estructuras de los edificios nunca forman una unidad completa y cerrada en sí misma. El Partenón no admite que se le añada ninguna nave más; se destruiría su unidad interna que trata de imitar la unidad autónoma de la фúoı c tanto terrestre como celeste. Igual se diga de las plantas en forma de cruz de las iglesias románicas o góticas. Por el contrario, la mezquita de Córdoba, por ejemplo, no solo admitió los añadidos a la primitiva de Abd alRahmân I, los de Abd al-Rahmân II, al-Hakam II y Almanzor, sino que con ellos resultó mucho más bella: no había en su planta una unidad conclusa. Y todo ello, porque uno, solo es Dios, el a priori supuesto de toda obra de arte musulmana.

\section{LOS LUGARES NATURALES DE LA NATURALEZA Y EL ESPACIO}

Otra de las características que considerábamos en el concepto de naturaleza y espacio clásico era el de su heterogeneidad. No era indiferente el arriba y el abajo y las demás posiciones, así como los movimientos y direcciones hacia esos lugares. En este sentido, las torres románicas y góticas tenían su doble sentido deíctico hacia el cielo, a la vez que ejercían de tirantes que arrastraban la materia deleznable hacia lo superior y divino. El minarete musulmán puede tener también ese sen-

20 Kamâl Bullâta, «Geometría de la lengua y gramática de la geometría», en Cuadernos de la Alhambra, Granada, 27 (1991), p. 11-26. 
tido, pero, sobre todo posee otro más importante, el puramente funcional, aparte de ser un elemento de un gran valor decorativo y estético. Es que la finalidad del minarete es la de ser el lugar apropiado para llamar desde arriba a la oración mediante la voz humana o para poner una luminaria que desde lejos se vea por la noche señalando el momento de hacer la oración ritual. Porque minarete viene de "manâr», que significa lugar donde se pone esa luz. Mientras que su otro nombra es el de «mi'dhana» es decir, el lugar donde se pone el «mu'adhin» o almuédano para llamar cinco veces al día con su voz a los fieles a la oración.

Por otra parte, la estructura interna de las iglesias románicas y góticas suponen un espacio marcadamente jerárquico porque expresan un tipo de religiosidad también esencialmente jerárquico: a Dios Padre, por el Hijo, Jesucristo, el mediador universal; a Cristo, mediante su Madre, María; a todos ellos, a través de los Santos; y en este mundo, la clara jerarquía que va desde el Papa, cardenales, obispos, sacerdotes, hasta los fieles, sin contar con los reyes que lo eran por la gracia de Dios. Todo ello se plasma en un espacio en el interior de los templos donde cada uno de estos elementos de la jerarquía tiene «su lugar natural»: altar, sitiales, coro etc.

La mezquita, por el contrario, expresa un espacio homogéneo, plano, por dos razones. Una, porque supone nada más que la sacralización de un espacio horizontal, uniforme, cual es el del mundo por encima del cual solo hay un ser, el de Dios, siendo todo lo demás exactamente igual en dignidad y grandeza. Y, en concreto, en cuanto a los hombres, solo se diferencian por una razón, por su fe, como dice el Corán: «iHombres! [...] Para Dios, el más noble de entre vosotros es el que más le teme. Dios es omnisciente, está bien informado». ${ }^{21}$ Por otro lado, la religión musulmana excluye toda mediación entre el hombre y Dios: el creyente se las ha de arreglar directamente con su Creador, desde lo más íntimo de la conciencia. Por tanto, la mezquita ha de reflejar también un espacio igualitario en el que cada uno de los fieles se comunique directamente con Dios. Y esa comunicación ha de empezar por reconocer la grandeza de su Creador, Allâh al-Akbar, Dios el más grande. En consecuencia el primer acto que el hombre debe hacer ante El es el de prosternarse. Por eso la mezquita se llama en árabe «masyid», que significa «lugar de prosternación». En consecuencia, para que exista una mezquita basta con un suelo horizontal donde todos son iguales y donde se puede el creyente inclinar ante su Señor. Y ese espacio horizontal es automáticamente «harâm», sagrado, a diferencia del espacio natural o profano del exterior, porque desde él es desde donde el hombre se relaciona con Dios. Por eso, en ausencia de la mezquita, el creyente ora sobre una alfombra que hace las funciones de sacralización del espacio que tiene el suelo de la mezquita. $Y$ de igual forma, en ausencia de ese suelo o de una alfombra, cumple la misma función el demarcar simbólicamente con el dedo un cuadrado en el suelo en cuyo interior se hace la oración. Y tan sagrado es ese espacio, tan distinto de lo profano y cotidiano que para acceder a él hay que purificarse antes y despojarse del calzado que pudiera introducir en ese espacio suciedades y elementos del espacio profano.

Pero aûn hay más en relación a la heterogeneidad del espacio y de la naturaleza. Los templos cristianos se orientan hacia Oriente por tres razones. Una, porque fue en Oriente donde nació Cristo. Otra, porque en Oriente es donde nace el día, la luz, la vida, el sol; también los griegos solían orientar sus templos en esa dirección y por el mismo motivo. Y, por fin, para que la luz entre en 
la mañana por el ábside donde está el altar y el tabernáculo, y siga penetrando al atardecer por el rosetón de la entrada.

La orientación de las mezquitas, en cambio, es por completo distinta. He dicho que para que haya una mezquita basta con que haya un suelo sacralizado donde prosternarse ante Dios. Pero es preciso otro elemento: una pared, llamada «qibla», que mire no hacia oriente sino hacia la Kàaba en la Meca y un nicho en su centro que se llamá «mihrâb». Ya no se trata solo de que fue allí donde nació el Profeta. Es que la Ka'aba representa el origen del monoteísmo ya que allí se supone que Abraham, el primer creyente en un solo Dios que se sometió por completo a El, ayudado por su hijo Ismael, construyó el primer templo en su honor. Más aún: dijo el Profeta: «iQue constituyáis una comunidad que invite al bien ordenando lo que está bien y prohibiendo lo que está mal! [...]. Sois la mejor comunidad humana que jamás se haya suscitado» ${ }^{22}$ lo cual significa lo siguiente: la comunidad religioso-política islámica, ya no se basa en razones históricas, raciales, lingüísticas sino en el solo y simple hecho de creer en un solo Dios, en ordenar la práctica del bien y en evitar el mal. Es entonces cuando el islam aspira a una universalidad de toda la humànidad, por encima de razas y lenguas, la llamada «umma» o comunidad total de todos los hombres. Esa unidad humana de creyentes queda simbolizada por la orientación hacia la Kàaba estableciéndose así un espacio único humano centrado en el mayor símbolo de la fe cual es aquel cuadrado que está en el interior de la gran mezquita de la Meca. Mirando a ella en la oración ritual, orientando el espacio de las mezquitas en esa dirección, todos los musulmanes se sienten unidos en vida, lo mismo que tras la muerte, enterrados directamente bajo tierra, también lo hacen de cara a ese centro del espacio universal, de la historia y de la fe. Es así, también, como focalizando radialmente hacia la Meca todo el espacio terrestre, éste queda sacralizado, al igual que el espacio temporal de la vida del creyente queda sacralizado por el hecho de peregrinar al menos una vez en la vida a la Meca.

\section{EL ESPACIO Y LA NATURALEZA BAJO EL CONTROL DE LA RAZÓN O DE LA IMAGINACIÓN}

He dicho desde el comienzo que en el arte del islam la Existencia y la Unidad de Dios se suponían como un a priori, que no se representaba la imagen de Dios ni se apuntaba en modo alguno a ella. La orientación hacia la Meca no es una orientación hacia Dios sino hacia algo tan natural como es el centro de toda la comunidad islámica y el origen de la fe en un solo Dios. En el arte cristiano occidental, en cambio, la imaginería, la pintura sobre los paramentos, las vidrieras nos hablan de hechos muy concretos que el creyente ve y puede aprehender su sentido o bien directamente con la razón, o bien utilizando ésta si es que se trata de símbolos o alegorías. La imaginación en el artista tendrá el papel de saber configurar personajes, hechos, historias que nunca ha presenciado o también el de pergeñar símbolos 0 alegorías que enseñen al creyente las grandes verdades religiosas y morales del cristianismo. La razón, entonces, lógica, simbólica o alegórica, ayudada por la imaginación, será la encargada de, por un lado, de parte del artista, de estructurar matemática y propor- 
cionalmente el espacio que expresa en su obra de arte y, por otro, del lado del contemplador, de descifrar con la misma razón lógica, simbólica y alegórica, el contenido y sentido del espacio y naturaleza expresados en el arte.

En el islam, en cambio, la razón se encargará también, junto con la imaginación, de estructurar la obra de arte, expresando el espacio y naturaleza que he descrito más arriba como propios del islam. La razón, además, será la encargada de elaborar los entrelazados geométricos y las proporciones matemáticas de sus obras de arte. ${ }^{23}$ Sin embargo, la imaginación desempeñará un papel primordial, por encima de la razón, la cual estará al servicio de aquella, tanto en el artista como en el contemplador. El tema lo han subrayado autores como Ibn Hazm de Córdoba, Ibn Arabî de Murcia y, en general, todos los autores sufies. Y ello es así porque con todo el matematicismo, proporciones y armonía que vuelca el artista musulmán en sus obras para expresar la naturaleza y el espacio islámicos, lo que se está suponiendo es la existencia de un Dios que no podemos conocer ni con los sentidos ni con la razón. Es por ello por lo que el único registro que le queda al hombre es el de la imaginación y el del sentido de la belleza que embarga todos sus sentidos y que está suponiendo la Belleza del Creador de esa naturaleza y espacio bellos. Digamos que en el arte musulmán no se trata de descifrar con la razón alegorías o símbolos, sino de descubrir (kashf) un oculto (bâtin) tras las formas aparentes y visibles (zâhir) mediante la imaginación (jayâl), términos todos propios del sufismo. Se trata de un esoterismo incrustado en el arte. Un esoterismo que el artista provoca con su imaginación para que el contemplador se sumerja en un halo de belleza y de misterio que le recuerde que solo tiene un Señor, un Unico Dios Bello. La misma tradición invita a que el hombre se lance a una interpretación esotérica de la naturaleza y de la Revelación. Dice un had^th: «El Coran tiene una apariencia externa y una profundidad oculta, un sentido exotérico y otro esotérico; a su vez, este sentido esotérico encierra otro sentido esotérico (cada nivel contiene otro nivel, a imagen de las Esferas Celestes embutidas unas en otras); y así sucesivamente hasta siete sentidos esotéricos (siete niveles de profundidad oculta)».

Tan importante es el papel de la imaginación que desvela el sentido oculto y misterioso de todo, y en especial del arte, que la estética que se puede extraer del pensamiento de Averroes no tuvo ninguna repercusión en el mundo musulmán ni fue expresiva del sentido del arte y de la belleza del mismo. De sus comentarios a la Poética y Retórica de Aristóteles, así como de otros comentarios al Estagirita y de sus obras de inspiración personal, se extrae una estética que se centra únicamente en el uso correcto de la razón que es la que guía al artista en la ejecución de su obra, cuyas características han de ser su veracidad, su claridad, su orden matemático, su exactitud. La imaginación queda relegada a un segundo término y sometida a la razón. Y lo mismo se diga del contemplador: ha de ser su razón la que juzgue de la belleza o fealdad del objeto. La estética de Averroes, así como el resto de su pensamiento, donde tuvo una gran repercusión fue en el Occidente Europeo medieval y renacentista, cuando sus obras fueron traducidas al latín.

23 Ver a este respecto: Prieto y Vives, A., El arte de la lacería, Colegio de Ingenieros de Caminos, Madrid, 1997 y «La simetría y la composición de los tracistas musulmanes», en Investigación y Progreso, n. 3, Madrid, (1932), p. 33-45. 
Es así como la naturaleza y el espacio quedan expresados en el arte medieval dependiendo del concepto que de ambos se tienen en las dos religiones monoteístas, cristianismo e islam. Y esta concepción de la naturaleza y el espacio está condicionada a su vez por los legados culturales que han recibido cada una de las dos culturas y por las creencias religiosas que tienen a partir de un mismo monoteísmo y creacionismo. Basten estas breves indicaciones que pueden servir de cierto cauce para análisis posteriores.

Joaquín Lomba Gran Vía, 42, $1^{\circ}$ izda. 50005. Zaragoza. e-mail: jlomba@posta.unizar.es 